Sarah D. Moral, MD

Ann Kathleen C. Barlin, MD

Jose M. Acuin, MD, MSc (Clin Epi)

Department of Otolaryngology Head \& Neck Surgery The Medical City Hospital

Pasig City, Philippines

\section{Clinical Profile of Post-Tonsillectomy Bleeding: A 30-Month Institutional Review}

\begin{abstract}
Objective: To determine the prevalence of post-tonsillectomy bleeding in our institution and to describe the clinical characteristics, tonsillectomy techniques and post-tonsillectomy bleeding intervention in these patients.
\end{abstract}

\section{Methods:}

Design: Observational descriptive study

Setting: Tertiary private hospital

Population: All patients who were treated for post-tonsillectomy bleeding were retrospectively reviewed from medical records of all patients who had undergone tonsillectomy between January 1, 2007 and June 30, 2009. Age and sex, indication for surgery, tonsil grade, Body Mass Index (BMI), surgical technique, post-operative medications, length of hospital stay, interval between tonsillectomy and onset of bleeding and interventions to address postoperative bleeding were noted.

Results: Of the 662 patients who underwent tonsillectomy, 37 (5.6\%) were managed for postoperative hemorrhage. Most had grade 2 or 3 tonsils (18 or $48.6 \%$ and 16 or $43.2 \%$ respectively) and were obese ( 25 or $67.5 \%$ ). The highest proportion of post-operative bleeding was $9.2 \%$ for bipolar cauterization technique (18 of 196 patients) followed by $7.4 \%$ with cold knife, monopolar cauterization and suturing ( 11 of 148 patients); $6.9 \%$ with harmonic scalpel ( 2 of 29 patients); $6.5 \%$ with monopolar and bipolar cauterization ( 3 of 46 patients), and 2.8\% for cold knife or Fischer knife (3 of 109 patients). Seven patients (18.9\%) required blood transfusion. Onset of bleeding occurred between 4-12 days following surgery (mean: 8 days). Possible causes of bleeding included heavy physical activity and cough but most had no identifiable cause. Majority of the patients ( 29 out of 37 ) required surgical exploration under general anesthesia.

Conclusion: Post-tonsillectomy bleeding is still a clinically significant complication despite advances in surgical techniques. Surgeons must always consider trade-offs between benefits and risks of the procedure and be continually vigilant of this potentially serious complication.

Keywords: Post-tonsillectomy bleeding, tonsillectomy techniques

Tonsillectomy is still one of the most common surgical procedures performed by otolaryngologists. Different techniques have evolved through time but the indications and complications have not changed much.

The most common indications for tonsillectomy are recurrent or chronic tonsillitis, surgical augmentation of the airway, and malignancy. ${ }^{1}$ Post-operative hemorrhage is still the most common complication which causes subsequent absence from school or work. ${ }^{2}$ Occurrence of post-tonsillectomy hemorrhage is unpredictable and potentially-life threatening. It entails 
substantial consequences that can be detrimental for both patients and doctors. The cost of a second admission, longer hospital stay or a return to the operating room cannot be taken lightly. Most importantly, posttonsillectomy bleeding is potentially life threatening and can degrade the patient's quality of life. For the surgeon, this complication can bring about emotional and professional trauma that can erode confidence.

The different surgical techniques have varying post-operative bleeding rates reported in the literature. A retrospective study of 494 patients by Ali et al. showed rates to be highest with bipolar cautery and lowest with cold knife and suturing. ${ }^{3}$ A retrospective study by Lowe and van der Meulen involving 13,554 patients showed that coblation tonsillectomy had a higher relative risk of post-operative bleeding compared with cold steel. ${ }^{4}$ Kristensen et al. also reported higher postoperative bleeding rates for coblation than for scalpel-snare-cautery techniques in a retrospective chart review of 632 patients. ${ }^{6}$ On the other hand, Collison ${ }^{2}$ et al. found a $4 \%$ post-operative bleeding rate out of 430 tonsillectomies performed by 2 surgeons using cold dissection and snare for removal of tonsils and Valley Lab (Tyco Healthcare group LP, Boulder, Colorado, USA) suction cautery for hemostasis and Windfuhr et al. reported a $2.7 \%$ bleeding rate out of 602 patients who underwent tonsillectomy with scissors and snare, and hemostasis with suture ligation and gauze pressure. ${ }^{5}$

This paper aims to determine the prevalence of post-tonsillectomy bleeding in our institution and to describe the clinical characteristics, tonsillectomy techniques and post-tonsillectomy bleeding intervention in these patients.

\section{METHODS}

The medical records of all patients who had undergone tonsillectomy in our institution between January 1, 2007 and June 30, 2009 were retrospectively reviewed. All patients who were managed for posttonsillectomy hemorrhage (defined as any bleeding that required medical attention) during the said time period were included in the present study. This included patients who developed bleeding during the same confinement for the tonsillectomy as well as those who were previously discharged but were readmitted due to post-tonsillectomy bleeding. Primary hemorrhage was defined as onset of bleeding less than 24 hours post tonsillectomy and secondary hemorrhage was defined as onset of bleeding more than 24 hours post tonsillectomy.

A standard data collecting form (Appendix) was used to extract the following data from each record: 1) age and sex, 2) tonsil grade and Body Mass Index (BMI), 3) indication for the procedure, 4) surgical technique including method of removal and hemostasis, 5) postoperative medications, 6) length of hospital stay, 7) number of hours from tonsillectomy to the report of post-operative bleeding , 8) possible cause of bleeding identified, and 9) intervention or treatment for postoperative bleeding including blood transfusion. The post-tonsillectomy bleeding patients included those managed by re-operation or by conservative measures (defined as control outside the operating room by means of silver nitrate cautery stick and continous ice water gargle).

\section{RESULTS}

Of the 662 patients who had undergone tonsillectomy at our institution during the 30-month study period, 37 patients (5.6\%) were managed for post-operative hemorrhage and were included in this study.

Their ages ranged between 5 and 54 years old, with a mean age of 33 (+/- 11) and a male to female ratio of 5:1. Most patients had either grade 2 or grade 3 tonsils ( 18 or $48.6 \%$ and 16 or $43.2 \%$, respectively). Most patients were obese (class I or BMI of $25-29.9,18$ or $48.6 \%$; class II or $\mathrm{BMI}>30,7$ or $18.9 \%$ ). The most frequent indication for tonsillectomy was recurrent tonsillitis followed by obstructive sleep apnea (OSA), most of whom were severe by polysomnography (Table 1).

Five different tonsillectomy techniques were used (Table 2). Of the 37 patients who had post-tonsillectomy bleeding, 29 (78\%) or roughly 4 out of 5 required re-operation. About half of the bleeds (18 or 48.7\%) had undergone bipolar cautery, three quarters (14 or $77.8 \%$ ) of whom had to be re-operated. About one-third of the bleeds (11 or 29.7\%) had undergone cold knife with monopolar cautery, all of whom had to be re-operated. Seven of the 37 patients had also undergone blood transfusion.

Most of the post-tonsillectomy bleeding involved secondary hemorrhage (28 or $75.7 \%$ ), with onset of bleeding occurring between 4-12 days after surgery (mean: 8 days).

\section{DISCUSSION}

Tonsillectomy techniques and instruments have evolved over the centuries, with aims that have included decreasing operating time and intraoperative blood loss. ${ }^{\text {? }}$

The different tonsillectomy techniques have been associated with varying intra and post operative bleeding rates. Pizzuto in $2000^{8}$ found that among the most commonly used techniques of cold dissection, hot knife dissection and bipolar diathermy dissection, intraoperative blood loss was far less with electrocautery than with cold dissection. He further concluded that the bipolar technique was a better choice on account of less bleeding, both intra and post-operatively, shorter recovery period and fewer days off from work and school. ${ }^{8}$

Reports comparing ligation with cautery attributed a higher rate of primary bleed to the use of suture ligation for hemostasis, and a more significant secondary bleed with the use of cautery. Although 


\section{ORIGINAL ARTICLES}

Philipine Journal Of Otolaryngology-Head And Neck Surgery

Vol. 25 No. 2 July - DecemBer 2010

PJOHNS

the use of cautery was effective in preventing primary hemorrhage, there was a tendency to a deeper and more extensive zone of necrosis and subsequent exposure of larger vessels when sloughing of the eschar occured. ${ }^{2.5}$ This may corroborate the results of this study where a majority of the patients experiencing secondary hemorrhage underwent cauterization.

The importance of strict adherence to indications for tonsillectomy

\section{Table 1. Patient Characteristics \& Indications for Tonsillectomy}

\begin{tabular}{|c|c|c|}
\hline Patient characteristics & & n (\%) \\
\hline \multirow[t]{5}{*}{ Age } & $0-10$ & $1(2.7 \%)$ \\
\hline & $11-21$ & $2(5.4 \%)$ \\
\hline & $22-32$ & $18(48.6 \%)$ \\
\hline & $33-43$ & $10(27 \%)$ \\
\hline & $44-54$ & $6(16.2 \%)$ \\
\hline \multirow[t]{2}{*}{ Gender } & Male & $32(84 \%)$ \\
\hline & Female & $5(16 \%)$ \\
\hline \multirow[t]{4}{*}{ Tonsil Grade } & Grade I & $2(5.4 \%)$ \\
\hline & Grade II & $18(48.6 \%)$ \\
\hline & Grade III & $16(43.2 \%)$ \\
\hline & Grade IV & $1(10.8 \%)$ \\
\hline \multirow[t]{5}{*}{ Body Mass Index } & Underweight $(<18.5)$ & $1(2.7 \%)$ \\
\hline & Healthy $(18.5-22.9)$ & $5(13.5 \%)$ \\
\hline & Overweight (23-24.9) & $6(16.2 \%)$ \\
\hline & Obese I (25-29.9) & $18(48.6 \%)$ \\
\hline & Obese II (>30) & $7(18.9 \%)$ \\
\hline \multirow{12}{*}{$\begin{array}{l}\text { Indications for } \\
\text { tonsillectomy }\end{array}$} & Recurrent Tonsillitis & $19(51.3 \%)$ \\
\hline & $\geq 4 / \mathrm{yr}$ & $10(52.6 \%)$ \\
\hline & Tonsillitis & $9(47.3 \%)$ \\
\hline & Obstructive Sleep Apnea & $15(40.54 \%)$ \\
\hline & Polysomnography & 13 \\
\hline & moderate & $3(23 \%)$ \\
\hline & severe & $8(61.5 \%)$ \\
\hline & not mentioned & $2(15.4 \%)$ \\
\hline & CPAP yes & $1(6.6 \%)$ \\
\hline & no & $3(20 \%)$ \\
\hline & not mentioned & $11(73.3 \%)$ \\
\hline & Others (tonsillar mass) & $3(8.1 \%)$ \\
\hline
\end{tabular}

Table 2. Post-tonsillectomy bleeds and interventions by surgical technique

\begin{tabular}{|l|r|r|r|}
\hline Surgical Technique & \multicolumn{1}{|l|}{$\begin{array}{l}\text { Post-tonsil } \\
\text { bleed }\end{array}$} & \multicolumn{2}{|l|}{$\begin{array}{l}\text { Type of intervention to control } \\
\text { post-operative bleed }\end{array}$} \\
\cline { 3 - 4 } & \multirow{2}{*}{$\begin{array}{l}\mathbf{n}(\% \text { of total) } \\
\text { (a) }\end{array}$} & $\begin{array}{l}\text { Surgical } \\
\mathbf{n}(\% \text { of a) } \\
\text { (b) }\end{array}$ & $\begin{array}{l}\text { Non-surgical } \\
\mathbf{n}(\% \text { of a) } \\
\text { (c) }\end{array}$ \\
\hline Cold knife + Chromic & $3(8.1 \%)$ & $2(67 \%)$ & $1(33 \%)$ \\
\hline Cold knife + monopolar & $11(29.7 \%)$ & $11(100 \%)$ & $0(0 \%)$ \\
\hline Bipolar cautery & $18(48.7 \%)$ & $14(77.8 \%)$ & $4(22.2 \%)$ \\
\hline Bipolar + monopolar & $3(8.1 \%)$ & $2(67 \%)$ & $1(33 \%)$ \\
\hline Harmonic scalpel & $2(5.4 \%)$ & $0(0 \%)$ & $2(100 \%)$ \\
\hline Total & 37 & $29(78.3 \%)$ & $8(21.6 \%)$ \\
\hline
\end{tabular}

cannot be understated considering its complications, particularly hemorrhage. Almost half (15/37 or $40.54 \%$ ) of the patients with bleeding in our study had Obstructive Sleep Apnea (OSA) as an indication. Perhaps the relatively narrow oropharynx in patients with OSA made exposure difficult, resulting in a tendency to over-retract the tonsils medially. This could conceivebly overstretch tonsillar bed vessels and cause immediate or delayed intraoperative bleeding necessitating hemostasis. Perhaps a first-line trial of CPAP in OSA patients should precede surgical options to minimize these complications of tonsillectomy.

Post-tonsillectomy hemorrhage was secondary in most of our patients. Secondary bleeding has not received as much attention as primary bleeding in the literature. This greater emphasis on primary bleeding may be attributable to the belief that it was more common and more serious ${ }^{9}$ but there are reports of delayed bleeding as long as 3 weeks following surgery that required surgical management under general anesthesia. ${ }^{5}$ There were no episodes of recurrent post-operative hemorrhage in our series.

The loss of blood notwithstanding, minimizing the incidence of this complication was important because post-operative bleeding can lead to airway compromise. The need for additional intervention such as blood transfusion increased costs and overall inconvenience for doctors and patients alike.

As for possible inciting events for post-tonsillectomy bleeding, a majority of the patients did not have an identifiable cause while others reported early resumption of physical exertion or vigorous coughing. Giving thorough home care instructions should not be taken lightly because the activities of patients after discharge from hospital can contribute significantly to the occurrence of bleeding.

All the seven surgeons involved in this study were reasonablyexperienced consultants with an average of 8 years and a range of 512 years of practice. The small sample size did not allow us to explore differences in the surgeons'clinical experience and their association with post-operative bleeding. However we can not discount the possibility that a clinically important association does exist and that surgical skill, rather than technique, could primarily influence complication rates.

Another potential limitation of this study lies in the method of identifying patients with post-tonsillectomy bleeding. It is possible that some patients with post-operative bleeding may have sought care at another facility without informing their original surgeon. This selection bias may further underestimate our post-tonsillectomy bleeding rate.

Post-tonsillectomy bleeding is still a clinically significant complication despite advances in surgical techniques. Surgeons must always consider trade-offs between benefits and risks of the procedure and be continually vigilant of this potentially serious complication. 


\section{APPENDIX}

\section{Checklist for Post Tonsillectomy Bleed Patients (2007-2009)}

NAME:

AGE:

DATE OF OPERATION:

CONSULTANT:

FIRST ASSIST:

INDICATION FOR TONSILLECTOMY: (check one)

o Recurrent Tonsillitis (RT)

\# of documented bouts per year:

\# of years w/ RT:

Medicines taken:

o OSA (circle one)

Witnessed apnea?

PSG?

Results of PSG

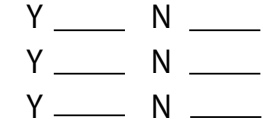

Cephalometry?

Mild __ Moderate Severe

Cephalometric values:

CPAP trial?

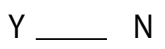

$$
\mathrm{N}
$$

Y

$\mathrm{N}$

If yes, how long?

o Other indications (halitosis, biopsy etc). Pls. Indicate

\section{PHYSICAL EXAMINATION}

o Tonsil grade 1 2

3

4

o Other pertinent oral cavity findings:

o BMI:

INTRA-OP DETAILS

Technique : (check one)

o Cold knife

o Cold knife + Monopolar cautery

- Bipolar cautery

o Monopolar + bipolar cautery

o Harmonic scalpel

o OTHERS

Hemostasis:

o Suturing

o Monopolar cautery

o Bipolar cautery

o Harmonic scalpel

Other surgeries performed with tonsillectomy:

Blood loss:

POST-OP MEDICATIONS:

LENGTH OF HOSPITAL STAY: days

\section{LENGTH OF TIME THAT HAD PASSED BETWEEN TONSILLECTOMY AND} ONSET OF BLEEDING?

$0<24$ hours: hrs post tonsillectomy

$0>24$ hrs: days post tonsillectomy

INTERVENTION DONE:

o Brought back to OR: suturing cautery

o Controlled conservatively: Ice gargle cautery stick packed with gauze IDENTIFIED POSSIBLE CAUSE OF BLEEDING:

o Ate hard food. Indicate food

o Physical activity/exertion. Indicate activity

o Cough

o None

HEMOGLOBIN PRE-TONSILLECTOMY: HEMOGLOBIN ON RE-ADMISSION (POST TONSIL BLEED): BLOOD TRANSFUSION DONE? $\quad \mathrm{Y} \quad \mathrm{N}$ If yes, indicate blood component and how many:

\section{ACKNOWLEDGMENT}

The authors would like to acknowledge the ENT surgeons who generously provided pertinent data for the completion of this study. This paper has supplemented the authors' learning regarding post-operative bleeding after Tonsillectomy. It is the authors' intention that this paper provides more understanding regarding the mechanisms and factors that contribute to this complication.

\section{REFERENCES}

1. Bhattacharyva N. Evaluation of post-tonsillectomy bleeding in the adult population. Ear Nose Throat J, Aug 2001; 80(8): 544-9.

2. Collison PJ, Mettler B. Factors associated with post-tonsillectomy hemorrhage. Ear Nose Throat J, Aug 2000; 79(8): 640-2.

3. Ali RB, Smyth $D$, Kane R, Donnelly M. Post-tonsillectomy bleeding: A regional hospital experience. Ir J Med Sci. Dec 2008; 177(4):297-301

4. Lowe $D$, van der Meulen J. Tonsillectomy technique as a risk factor for postoperative hemorrhage- National prospective tonsillectomy audit. Lancet. Aug 2004; 364(9435): 697-702

5. Windfuhr JP, Schloendorff G, Sesterhenn AM, Prescher A, Kremer B. A devastating outcme after adenoidectomy and tonsillectomy: Ideas for improved management. Otolaryngol Head Neck Surg. Feb 2009; 140(2): 191-6

6. Kristensen S, Tveteras K. Post-tonsillectomy haemorrhage: A retrospective study. Clin Otolaryngol Allied Sci. Dec 1984; 9(6): 347-50

7. Younis RT, Lazar RH. History and current practice of tonsillectomy. Laryngoscope. Aug 2002; 112(8 Pt 2 Suppl 100); 3-5.

8. Pizzuto MP, Brodsky L, Duffy L, Gendler J, Nauenberg E . A comparison of microbipolar cautery dissection to hot knife and cold knife cautery tonsillectomy. Int J Pediatr Otorhiolaryngol. May 2000; 52 (3): 239-246.

9. Gabalski EC, Mattucci KF, Setzen M, Moleski P. Ambulatory tonsillectomy and adenoidectomy. Laryngoscope. Jan 1996; 106(1 Pt 1): 77-80

10. Hainer BL. Fundamentals of electrosurgery. J Am Board Fam Pract. Nov- Dec 1991; 4(6):419-26

11. Boughton RS, Spencer SK. Electrosurgical fundamentals. J Am Acad Dermatol. April 1987;16(4):862-7.

12. Walker RA, Syed ZA. Harmonic scalpel tonsillectomy versus electrocautery tonsillectomy: a comparative pilot study. Otolaryngol Head Neck Surg. Nov 2001; 125(5):449-455

13. Koltai PJ, Solares CA, Mascha EJ, Xu M. Intracapsular partial tonsillectomy for tonsillar hypertrophy in children. Laryngoscope. Aug 2002; 112(8 Pt 2 Suppl 100):17-19

14. Chan KH, Friedman NR, Allen GC, Yaremchuk K, Wirtschafter A, Bikhazi N, et al. Randomized controlled, multisite study of intracapsular tonsillectomy using low-temperature plasma excision. Arch Otolaryngol Head Neck Surg. Nov 2004; 130(11): 1303-7

15. Strom BL, Berlin JA, Kinman JL, Spitz PW, Hennessy S, Feldman H, et al. Parenteral Ketorolac and risk of gastrointestinal and operative site bleeding: a post-marketing surveillance study. JAMA. $1996 ; 275: 376-82$ 